\title{
Distraction or Connection? An Investigation of Social Media Use at Work
}

\author{
Manli Wu \\ University of Science and \\ Technology of China-City \\ University of Hong Kong \\ manliw1988@gmail.com

\section{J. Leon Zhao} \\ City University of Hong Kong \\ jlzhao@mail.cityu.edu.hk
}

\author{
Chen Yang \\ Shenzhen University \\ yangc@szu.edu.cn
}

\author{
Chuang Wang* \\ South China University of \\ Technology \\ bmchwang@scut.edu.cn
}

\author{
Liang Liang \\ University of Science and \\ Technology of China \\ lliang@ustc.edu.cn \\ Sisi $\mathrm{Wu}$ \\ University of Science and \\ Technology of China-City \\ University of Hong Kong
}

cescewu@mail.ustc.edu.cn

\begin{abstract}
The use of social media in the workplace is controversial. In order to develop a good understanding of social media use at work, this study examines the effects of social media use from both positive and negative sides. Based on two-factor theory, this study proposes that social media use at work engenders distraction and perceived relatedness, which in turn influence job performance. This study further draws on resource matching theory to posit that the perceptual load of the job moderates the effects of social media use at work on distraction and perceived relatedness. A survey will be conducted to collect data and test the research hypotheses. In theoretical terms, this study is expected to contribute to information systems research by investigating both positive and negative outcomes of social media usage. In practical terms, this study sheds light on the usage and management of social media in the workplace.
\end{abstract}

\section{Introduction}

Social media have experienced an exponential increase in recent years, and been used for many purposes, such as information sharing [1], social communication [1], entertainment [2], or just spending time [3]. The growth of mobile technologies creates new opportunities to social media use, making it an indispensable part of daily lives. The ubiquity of social media has also penetrated the workplace and raised the interest of practitioners and scholars. Many attempts have been made to examine the outcomes of social media use, however, there seems to be very limited understanding about social media use in the workplace.
Of the limited research published to date, the use of social media in the workplace has been controversial and unquantified, with both positive and negative outcomes having been reported. Extant research tends to investigate the mechanism of social media use by considering its positive outcomes, such as social capital [2], knowledge sharing [4], and job performance [5]. For instance, Moqbel, Nevo, and Kock [5] found that the intensity of social media use at work is positively related to job performance. Similarly, Charoensukmongkol [6] elaborated that social media use at work has a positive and direct effect on job performance. In contrast, little work has been done on examining how social media use negatively affects job outcomes. Few extant studies suggested that using social media in the workplace may waste time and result in loss of work effectiveness [7]. More specifically, accessing to Facebook at work was found to cause 1.5 percent drop in productivity [8]. With these controversial findings, it is believed that the mechanism underlying social media use has not been well understood.

One common way to study social media use is to relate it to psychological outcomes [9]. In this study, we attempt to investigate employees' use of social media by considering both positive and negative psychological outcomes. Positively, it has been highlighted that users find it favorable to use social media since it entails them to build new connections and maintain existing connections with others [2]. In particular, users can rely on social media to fulfill their relatedness needs by connecting with working professionals, friends and family, in both working and personal time [10]. Negatively, one potential negative side of social media use lies in its distractive effect on job. A worker usually gets interrupted at least six to eight times a day, and such interruptions occupy $28 \%$ 
of the worker's day $[11,12]$. Some features of social media can lead to distraction if it is used at work. For instance, the reminders of new messages and new updates demand the recipient's immediate attention, regardless of the work at hand [12]. In addition, many people have social media dependence, and they are accustomed to checking social media accounts constantly, even during the work time [13].

Although efforts have been spent on expanding our understanding of the positive and negative effects of social media use, research in this area is relatively underdeveloped, mainly because it lacks empirically testable theories that can explain both sides of social media use simultaneously. Since distraction and perceived relatedness are direct psychological reactions of social media use, this study examines how social media use at work engenders distraction and perceived relatedness, which in turn affect job performance. In addition, individuals' cognitive ability in working memory is limited [14]. If the attentional resources available cannot fulfill requirements of the ongoing job, the job performance will be hampered. The question of whether attention can ever affect the perception of distractors is controversial. Therefore, this study attempts to fill the above research gaps and answer the following research question: whether and how social media use at work affects job performance? This study builds on two-factor theory (TFT) and resource matching theory (RMT) to develop the research model. A survey method will be employed to collect data and test the research model. Through this investigation, this study is expected to contribute to social media research by investigating both positive and negative effects of social media in the workplace.

\section{Theoretical background}

\subsection{Two-factor theory}

As a core variable in research and practice of Information Systems (IS), IT usage has been regarded as a strong predictor of IS success [15] and organization development [2]. Social media present a unique context for IS researchers to explore technology usage. Social media use has become one of the most common activities on the Internet [12]. Although researchers have advocated the benefits of social media, it should be noted that social media use could also bring negative consequences.

TFT was first proposed to explain factors that cause job satisfaction and dissatisfaction [16]. Then, TFT has been applied to considerable areas to explain phenomena like interpersonal trust and distrust [17], positive and negative emotions [18], and employee performance [3]. In recent years, this theory has emerged in IS research to explain technology use [16, 19]. To develop a better understanding of social media use, this study builds on TFT to examine both positive and negative outcomes engendered by social media use at work.

In consistency with TFT, social media use at work is not monolithically good or bad, and one can perceive both aspects simultaneously [19]. Incorporating social media into workplace is regarded as a two-edged sword [13]. On the positive side, social media use at work was found to foster social capital [20], promote knowledge transfer [4], improve sense of cultural belonging [21], and increase group effectiveness [7]. Although some studies have mentioned the negative side of social media use [7, 21], few of them explicitly examined it in relation to job performance. In large part, the focus on positive side is due to the desire to achieve good outcomes via technology usage. On the other side, opportunities for social media-related distraction have never been higher owing to the explosion of social media [13]. Hence, developing a comprehensive understanding of positive and negative outcomes of social media use at work is of great value. Building on TFT, this study identifies distraction and perceived relatedness as psychological outcomes of social media use, and examines their effects on job performance. Specifically, distraction refers to the avoidance from working because of social media use [22]. Perceived relatedness refers to one's feeling of being included and affiliated with others [23]. Although self-determination theory posits three psychological needs, namely competence, autonomy, and relatedness [23], this study mainly focuses on relatedness. Consistently, it has been highlighted that the crucial feature makes social media different from other communication media is its superiority in connecting people [24].

\subsection{Resource matching theory}

RMT is a theory that explains the effects of utilizing cognitive resources to process information for a given task [25]. It posits that information processing is more effective when the cognitive resources available to process the information fit those required for the task [26]. Although RMT has been applied and tested in the context of advertising, it has not been adopted by IS researchers to explain the effects of social media use on job performance. Two IS theories relating the notion of fit to performance are the cognitive fit theory and the task-technology fit theory. The former proposes that task performance improves when the information presentation format corresponds to the task requirement [27]. The latter posits that task 
performance will be enhanced when the capabilities of the information technologies fit the tasks being performed [28]. The two theories have been used to examine the effects of various information technologies.

Social media is a typical kind of information technologies. The notion of "fit" can thus be applied to investigate the effects of social media use on job performance. We use RMT rather than cognitive fit theory and task-technology fit theory for the following two reasons. First, both cognitive fit theory and tasktechnology fit theory emphasize the features of information technologies, such as information presentation format in cognitive fit theory and information technologies capabilities in tasktechnology fit theory [27, 28]. The current study, however, mainly focuses on the effects of social media use in the workplace, and it is the attentional resources allocation affected by social media use rather than the features of social media that affect job performance. Second, cognitive fit theory and task-technology fit theory primarily emphasize on the outcome of an ideal fit situation [25]. Despite that, RMT can also provide explanations for cognitive resource allocation upon social media content and the job. Hence, we use RMT in the current study to not only consider the notion of "fit", but also explore the attentional resource allocation between social media and the job.

It has been postulated that social media use at work can engender both positive (i.e., relatedness) and negative (i.e., distraction) psychological outcomes. We further propose that the effects of social media use are affected by the balance between the attentional resources available to process the job/task and those allocated to process social media content. Drawing on RMT, this study posits that social media use at work can result in less distraction when the amount of attentional resources left for the job matches the attention demanded for it. Conversely, social media use at work may cause high distraction when social media take up more attentional resources, and insufficient attention is left for the focal job.

\subsection{Job performance}

In this paragraph, we specify the outcome variable that we pursue. Among potential job outcomes, being able to perform well on the focal job is of great importance to people in the workplace. Prior studies have discussed various negative consequences of social media use, among which diminished performance is a relatively prevalent consequence and is concerned by practitioners. Considering that this study focuses on social media use at work, it is reasonable to examine job performance as the dependent variable in the current study. Job performance is the extent to which employees evaluate their own performance on the job [5].

\section{Hypotheses development}

Figure 1 depicts the research model of this study. As indicated in this model, social media use at work affects job performance via its effects on job distraction and perceived relatedness. Furthermore, the effects of social media on distraction and perceived relatedness vary upon the perceptual load of the job. We develop our hypotheses in the following paragraphs.

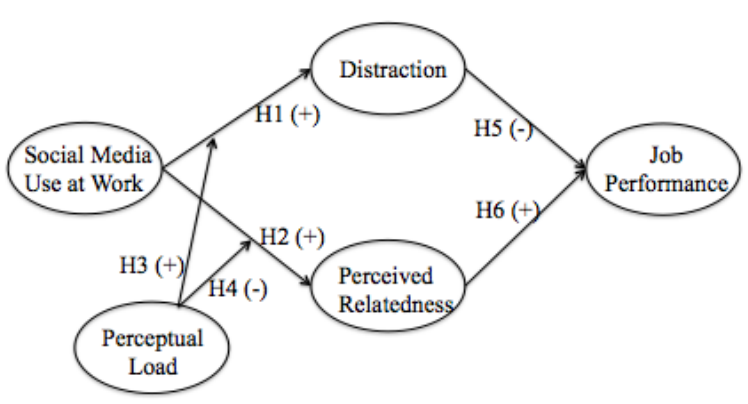

Figure 1. Research model

\subsection{Social media use at work}

Social media use has become one of the most common activities on the Internet [12]. The use of social media at work may cause external as well as internal distractions [29]. External distractions are usually initiated by sound and sight. Social media can remind users of new messages and updates. The reminders in forms of sound and sight may become distractions by introducing multiple tasks and diverting users' attention to non-work related information [10]. The checking habit of social media is a typical type of internal distraction [29]. The increasing use of mobile social media applications exacerbates users' checking habit whereby they constantly make brief inspections of the social media content. In addition, simply knowing that one's family and friends are available through social media can also be an internal distractor to one's job [12]. Consequently, we propose that social media use may divert attention to non-work-related information and cause distraction.

H-1: Social media use at work is positive related to job distraction. 
Social media use fulfills the needs of relatedness with professionals, family and friends in both professional and personal time [12]. First, social media serve as a channel through which users can exchange task-related information, ask for and provide real-time help, and collaborate on problem-solving during the work process [10]. Second, social media use entails a psychophysiological state that is characterized by high arousal and high positive valence [30]. In line of this reasoning, Wang and Tchernev [31] further examined media use during learning courses and posited that this form of multitasking is to satisfy affective needs rather than cognitive needs. The ability of social media to relate to family members and friends can fulfill users' affective needs [12]. Combining the above argument, it is reasonable to propose that social media use at work is positively related to perceived relatedness.

\section{H-2: Social media use at work is positively related to} perceived relatedness.

\subsection{The moderating effects of perceptual load}

Perceptual load is concerned with the perceptual demand of a job, which influences how the irrelevant information is processed [32]. According to RMT, the effects of social media use at work depend on users' allocation of attentional resources to the social media content and the job [25]. When the attentional resources allocation matches those required for the job and the social media, the effects of social media use are optimal. In this study, we propose that the perceptual load of the job moderates the effects of social media use on job distraction and perceived relatedness. On one side, when the job is of high conceptual load, a lot of attentional resources are required in order to complete it successfully [33]. Since attentional resources are limited [34], social media use at work may take up some attention that should have been allocated to the job, which results in mismatch between the attentional resources preserved for the job and those required. As such, social media use at work is regarded as distractive. In addition, although some attention has been spared to process social media content, high perceptual load reduces the brain response to social media content [35]. Therefore, the perceived relatedness associated with social media use is reduced.

On the other side, when the job involves low perceptual load, it does not require a great deal of cognitive resources to complete it [33]. Therefore, social media use is less distractive since employees can allocate enough attentional resources to match the demand of the job apart from processing social media content. Moreover, the low perceptual load guarantees that sufficient attentional resources are available for processing social media content. Thus, employees perceive high relatedness resulting from social media use in low perceptual load condition.

Overall, jobs with both high and low perceptual load require attentional resources, but the attentional demand imposed by social media is more distractive to job with high than low perceptual load. Oppositely, only when enough attention resources are spared to process social media content, perceived relatedness will increase.

H-3: The perceptual load of the job moderates the effect of social media use on distraction. Specifically, social media use will elicit more distraction when the perceptual load is high; social media use will elicit less distraction when the perceptual load is low.

H-4: The perceptual load of the job moderates the effect of social media use on perceived relatedness. Specifically, social media use will elicit less perceived relatedness when the perceptual load is high; social media use will elicit more perceived relatedness when the perceptual load is low.

\subsection{Effects on job performance}

Job distraction resulting from social media use has a negative effect on performance development. Since engaging in social media during work time can be regarded as a type of multitasking, the distractive effect can be explained by a multitasking perspective. First, employees need to spare some time to cope with the social media content, so distraction causes increased time to complete the primary work and results in inefficiencies in job performance [12]. Second, due to the limited cognitive resources, employees engage in their work with more shallow thinking at the expense of deep and comprehensive thinking when confronted with distraction from social media [36]. In addition, switching to social media while working also causes significant memory disruption [29], which undermines job performance. Third, the distraction from social media may pose challenges in mentality to return to the job [12]. The use of social media at work blurs the boundaries between work and life, and the family affairs and leisure issues may interfere with one's job responsibility [21]. Although present at work, employees may fail to perform to their best due to the lack of concentration, which consequently leads to diminished job performance.

H-5: Job distraction is negatively related to employees' job performance. 
Regardless of the distractive effect, perceived relatedness resulting from social media use can also influence job performance. First, employees who have a high level of relatedness with other organizational members tend to view their work environment as favorable, which facilitates the attainment of job goals and consequently increases job performance [37]. In contrast, employees who feel isolated from other organizational members are likely to regard the work environment as unsupportive, which is not conducive to realize job goals and consequently leads to reduce in job performance. Second, job performance can also be influenced by the emotional experiences one has on the job. Being included and affiliated with others, both work related and non-work related, gives rise to feelings of personal worth and comfort. Such feelings are associated with positive mood, which has been found to be a positive predictor of job performance [38]. In addition, relatedness can foster an atmosphere of support and encouragement, leading employees to feel less tension and stress, and creating a favorable job experience and job outcome [39]. Overall, we propose that perceived relatedness exerts a positive effect on job performance.

H-6: Perceived relatedness is positively related to employees' job performance.

\section{Research methodology}

To test the proposed hypotheses in the research model, we will employ a survey method, which ensures this study to capture the natural environment of social media use. Young educated adults will be recruited as participants for the following two reasons. First, social media are popular among the young educated population [12]. Second, the "always on" habit is widespread among young educated adults, so they may be more vulnerable to distraction [40]. Specifically, we plan to invite young knowledge workers to participate in the survey. It is common for the typical knowledge worker to experience a distractive work environment when social media is widely used. We will send invitation letters via popular social media platforms, WeChat for example, to recruit participants. On the cover page of the survey, we will specify our interest in social media use. Participants will be asked to recall their recent use of social media in the work time and self-report their psychological reactions to social media use and their job performance during this period. All constructs in this study will be measured via well-designed questionnaires. The items for measuring these constructs are developed by adapting the existing measurements to the current research context. The survey items and their sources are presented in the Appendix.

Apart from the variables examined in the research model, gender, age, self-regulation and multitasking preference are included as control variables to exclude confounding effects, because they have been reported to be associated with distraction and job outcomes [29, 41].

\section{Discussion and conclusion}

This study aims to develop a research model to explain how social media use at work affects job outcomes. Drawing on TFT, this study identifies job distraction and perceived relatedness as psychological outcomes of social media use, and examines their effects on job performance. This study further builds on RMT to propose that the levels of distraction and perceived relatedness resulting from social media use vary upon the perceptual load of the job.

This study is expected to have theoretical implications. First, this study focuses on examining social media use at work and the associated outcomes, thereby contributing to the growing body of IS research that investigates both the positive and negative outcomes of information technology use. More specifically, this study extends research domain that addresses the effects of social media from a psychological perspective, advancing theoretical understanding of the mechanism underlying social media use and job performance. Second, this study extends RMT to the context of social media use, and investigates the resource allocation between social media and the job. For instance, this study proposes that if the attentional resources allocated to the ongoing job match the requirement of the perceptual load, the distractive effects of social media will be reduced.

This study also has potential practical implications. First, this study has relevance for social media users. By understanding the effects of social media use on the job performance, social media users can become selfregulated to find a balance between social media use and their jobs to gain the benefits and avoid the detriments as a result of social media use. Second, this study sheds light on the management of social media use in organizations, as it guides practitioners to take advantage of the positive effects of social media and get rid of the negative effects of social media. Third, this study has implications for social media providers as they may attempt to understand the mechanism behind social media use. Negative usage experience may lead users to discontinue their social media use, which is a pivotal issue to be addressed by platform providers. 


\section{Acknowledgement}

The authors would like to thank the track chair and the anonymous reviewers for their precious comments and suggestions for improving the quality of this paper. The work was substantially supported by National Natural Science Foundation of China (Project No. 71471157, 71601080, 71701134), The Ministry of Education of China, Humanities and Social Sciences Project (Project No.16YJC630113, 16YJC630153), and Natural Science Foundation of Guangdong Province of China (Project No. 2017A030310427).

\section{References}

[1] Liu, I.L., Cheung, C.M., and Lee, M.K., "User Satisfaction with Microblogging: Information Dissemination Versus Social Networking", Journal of the Association for Information Science and Technology, 67(1), 2016, pp. 56-70.

[2] Ali-Hassan, H., Nevo, D., and Wade, M., "Linking Dimensions of Social Media Use to Job Performance: The Role of Social Capital", The Journal of Strategic Information Systems, 24(2), 2015, pp. 65-89.

[3] Sirdeshmukh, D., Singh, J., and Sabol, B., "Consumer Trust, Value, and Loyalty in Relational Exchanges", Journal of Marketing, 66(1), 2002, pp. 15-37.

[4] Cao, X., Guo, X., Vogel, D., and Zhang, X., "Exploring the Influence of Social Media on Employee Work Performance", Internet Research, 26(2), 2016, pp. 529-545.

[5] Moqbel, M., Nevo, S., and Kock, N., "Organizational Members' Use of Social Networking Sites and Job Performance: An Exploratory Study", Information Technology \& People, 26(3), 2013, pp. 240-264.

[6] Charoensukmongkol, P., "Effects of Support and Job Demands on Social Media Use and Work Outcomes", Computers in Human Behavior, 36(2014, pp. 340-349.

[7] Wang, C.-C., Yang, Y.Y.-H., and Tseng, C.-Y., "Always on Duty? The Positive and Negative Effects of Using Mobile Social Networking Tools for Work", PACIS, 2016, pp. 270.

[8] Nucleus, "Facebook: Measuring the Cost to Business of Social Networking", in (Editor, 'ed.'^'eds.'): Book Facebook: Measuring the Cost to Business of Social Networking, 2009

[9] Sheldon, K.M., Abad, N., and Hinsch, C., "A TwoProcess View of Facebook Use and Relatedness NeedSatisfaction: Disconnection Drives Use, and Connection Rewards It", Journal of Personality and Social Psychology, 100(4), 2011, pp. 766-775.
[10] Ou, C.X., and Davison, R.M., "Interactive or Interruptive? Instant Messaging at Work", Decision Support Systems, 52(1), 2011, pp. 61-72.

[11] Spira, J.B., and Feintuch, J.B., "The Cost of Not Paying Attention: How Interruptions Impact Knowledge Worker Productivity", Report from Basex, 2005,

[12] Brooks, S., "Does Personal Social Media Usage Affect Efficiency and Well-Being?", Computers in Human Behavior, 46(2015, pp. 26-37.

[13] North, M., "An Evaluation of Employees' Attitudes toward Social Networking in the Workplace", Issues in Information Systems, 11(1), 2010, pp. 192-197.

[14] De Jong, T., "Cognitive Load Theory, Educational Research, and Instructional Design: Some Food for Thought", Instructional science, 38(2), 2010, pp. 105-134.

[15] Delone, W.H., and Mclean, E.R., "The Delone and Mclean Model of Information Systems Success: A Ten-Year Update", Journal of Management Information Systems, 19(4), 2003, pp. 9-30.

[16] Park, S.C., and Ryoo, S.Y., "An Empirical Investigation of End-Users' Switching toward Cloud Computing: A Two Factor Theory Perspective", Computers in Human Behavior, 29(1), 2013, pp. 160-170.

[17] Lewicki, R.J., Mcallister, D.J., and Bies, R.J., "Trust and Distrust: New Relationships and Realities", Academy of management review, 23(3), 1998, pp. 438-458.

[18] Diener, E., Smith, H., and Fujita, F., "The Personality Structure of Affect", Journal of Personality and Social Psychology, 69(1), 1995, pp. 130-141.

[19] Cenfetelli, R.T., and Schwarz, A., "Identifying and Testing the Inhibitors of Technology Usage Intentions", Information Systems Research, 22(4), 2011, pp. 808-823.

[20] Mumford, M.D., Pathways to Outstanding Leadership: A Comparative Analysis of Charismatic, Ideological, and Pragmatic Leaders, Psychology Press, 2006.

[21] Gardner, W.L., Lowe, K.B., Moss, T.W., Mahoney, K.T., and Cogliser, C.C., "Scholarly Leadership of the Study of Leadership: A Review of the Leadership Quarterly's Second Decade, 2000-2009", The Leadership Quarterly, 21(6), 2010, pp. 922-958.

[22] Davis, R.A., Flett, G.L., and Besser, A., "Validation of a New Scale for Measuring Problematic Internet Use: Implications for Pre-Employment Screening", CyberPsychology \& Behavior, 5(4), 2002, pp. 331-345. 
[23] Chen, K.-C., and Jang, S.-J., "Motivation in Online Learning: Testing a Model of Self-Determination Theory", Computers in Human Behavior, 26(4), 2010, pp. 741-752.

[24] Kaplan, A.M., and Haenlein, M., "Users of the World, Unite! The Challenges and Opportunities of Social Media", Business horizons, 53(1), 2010, pp. 59-68.

[25] Tan, C.-H., Teo, H.-H., and Benbasat, I., "Assessing Screening and Evaluation Decision Support Systems: A Resource-Matching Approach", Information Systems Research, 21(2), 2010, pp. 305-326.

[26] Martin, B.A., Sherrard, M.J., and Wentzel, D., "The Role of Sensation Seeking and Need for Cognition on Web Site Evaluations: A Resource - Matching Perspective", Psychology \& Marketing, 22(2), 2005, pp. 109-126.

[27] Vessey, I., "Cognitive Fit: A Theory - Based Analysis of the Graphs Versus Tables Literature", Decision Sciences, 22(2), 1991, pp. 219-240.

[28] Goodhue, D.L., and Thompson, R.L., "Task-Technology Fit and Individual Performance", Mis Quarterly, 1995, pp. 213-236.

[29] Rosen, L.D., Carrier, L.M., and Cheever, N.A., "Facebook and Texting Made Me Do It: Media-Induced Task-Switching While Studying", Computers in Human Behavior, 29(3), 2013, pp. 948-958.

[30] Mauri, M., Cipresso, P., Balgera, A., Villamira, M., and Riva, G., "Why Is Facebook So Successful? Psychophysiological Measures Describe a Core Flow State While Using Facebook", Cyberpsychology, Behavior, and Social Networking, 14(12), 2011, pp. 723-731.

[31] Wang, Z., and Tchernev, J.M., "The "Myth" of Media Multitasking: Reciprocal Dynamics of Media Multitasking, Personal Needs, and Gratifications", Journal of Communication, 62(3), 2012, pp. 493-513.

[32] Sadeh, N., and Bredemeier, K., "Individual Differences at High Perceptual Load: The Relation between Trait Anxiety and Selective Attention", Cognition and Emotion, 25(4), 2011, pp. 747-755.

[33] Deshon, R.P., Brown, K.G., and Greenis, J.L., "Does Self-Regulation Require Cognitive Resources? Evaluation of Resource Allocation Models of Goal Setting", Journal of Applied Psychology, 81(5), 1996, pp. 595-608.

[34] Kanfer, R., and Ackerman, P.L., "Motivation and Cognitive Abilities: An Integrative/Aptitude-Treatment Interaction Approach to Skill Acquisition", Journal of Applied Psychology, 74(4), 1989, pp. 657-690.
[35] Lavie, N., "Attention, Distraction, and Cognitive Control under Load", Current directions in psychological science, 19(3), 2010, pp. 143-148.

[36] Carr, N., The Shallows: What the Internet Is Doing to Our Brains, WW Norton \& Company, 2011.

[37] Poon, J.M., Salleh, A.H.M., and Senik, Z.C., "Propensity to Trust as a Moderator of the Relationship between Perceived Organizational Support and Job Satisfaction", International Journal of Organization Theory and Behavior, 10(3), 2007, pp. 350-364.

[38] Stinglhamber, F., and Vandenberghe, C., "Organizations and Supervisors as Sources of Support and Targets of Commitment: A Longitudinal Study", Journal of Organizational Behavior, 24(3), 2003, pp. 251-270.

[39] Madjar, N., "Emotional and Informational Support from Different Sources and Employee Creativity", Journal of Occupational and Organizational Psychology, 81(1), 2008, pp. 83-100.

[40] Krasnova, H., Widjaja, T., Buxmann, P., Wenninger, H., and Benbasat, I., "Research Note-Why Following Friends Can Hurt You: An Exploratory Investigation of the Effects of Envy on Social Networking Sites among College-Age Users", Information Systems Research, 26(3), 2015, pp. 585-605.

[41] Wei, F.-Y.F., Wang, Y.K., and Klausner, M., "Rethinking College Students' Self-Regulation and Sustained Attention: Does Text Messaging During Class Influence Cognitive Learning?", Communication Education, 61(3), 2012, pp. 185-204.

[42] Fang, X., Hu, P.J.-H., Chau, M., Hu, H.-F., Yang, Z., and Sheng, O.R.L., "A Data-Driven Approach to Measure Web Site Navigability", Journal of Management Information Systems, 29(2), 2012, pp. 173-212.

[43] Santhanam, R., Sasidharan, S., and Webster, J., "Using Self-Regulatory Learning to Enhance E-Learning-Based Information Technology Training", Information Systems Research, 19(1), 2008, pp. 26-47. 


\section{Appendix. Measurement instruments}

\begin{tabular}{|c|c|c|}
\hline Construct & Items & $\begin{array}{l}\text { Sour } \\
\text { ces }\end{array}$ \\
\hline $\begin{array}{l}\text { Social Media } \\
\text { Use at Work } \\
\text { (SMU) }\end{array}$ & $\begin{array}{l}\text { SMU1: I often use social media to } \\
\text { obtain information. } \\
\text { SMU2: I regularly use social } \\
\text { media to maintain and strengthen } \\
\text { communications with others. } \\
\text { SMU3: What is your frequency of } \\
\text { usage of social media at work? }\end{array}$ & $\begin{array}{l}{[4]} \\
{[10]}\end{array}$ \\
\hline $\begin{array}{l}\text { Distraction } \\
\text { (D) }\end{array}$ & $\begin{array}{l}\text { D1: When I am using social } \\
\text { media, I don't think about my job. } \\
\text { D2: I find that I use social media } \\
\text { when I have job to do. } \\
\text { D3: I sometimes use social media } \\
\text { to procrastinate. } \\
\text { D4: I often use social media to } \\
\text { avoid doing unpleasant things in } \\
\text { my job. } \\
\text { D5: Using social media is a way } \\
\text { to forget about the jobs I must do } \\
\text { but don't really want to do. }\end{array}$ & [22] \\
\hline $\begin{array}{l}\text { Perceived } \\
\text { Relatedness } \\
(\mathrm{PR})\end{array}$ & $\begin{array}{l}\text { PR1: I feel a sense of contact with } \\
\text { people who care for me, and } \\
\text { whom I care for via using social } \\
\text { media. } \\
\text { PR2: I feel close and connected } \\
\text { with other people who are } \\
\text { important to me via using social } \\
\text { media. } \\
\text { PR3: I feel a strong sense of } \\
\text { intimacy with the people on social } \\
\text { media. } \\
\text { PR4: I am lonely via using social } \\
\text { media. [R] } \\
\text { PR5: I feel unappreciated by one } \\
\text { or more important people via } \\
\text { using social media. [R] } \\
\text { PR6: I have disagreements or } \\
\text { conflicts with people I usually get } \\
\text { along with on social media. [R] }\end{array}$ & [9] \\
\hline $\begin{array}{l}\text { Perceptual } \\
\text { Load (PL) }\end{array}$ & $\begin{array}{l}\text { PL1: It generally took me a lot of } \\
\text { perceptual efforts to process my } \\
\text { job. } \\
\text { PL2: I usually needed a lot of } \\
\text { thinking when deciding how to do } \\
\text { with my job. } \\
\text { PL3: In general, I spent a lot of } \\
\text { cognitive effort to finish my job. } \\
\text { PL4: Generally speaking, the } \\
\text { processing of my job was } \\
\text { cognitively demanding. } \\
\text { PL5: Overall, I incurred a } \\
\text { significant cognitive load when } \\
\text { trying to complete my job. }\end{array}$ & [42] \\
\hline
\end{tabular}

\begin{tabular}{|c|c|c|}
\hline $\begin{array}{l}\text { Job } \\
\text { Performance } \\
(\mathrm{JP})\end{array}$ & $\begin{array}{l}\text { JP1: My performance in my } \\
\text { current job is excellent. } \\
\text { JP2: I am very satisfied with my } \\
\text { performance in my current job. } \\
\text { JP3: I am very happy with my } \\
\text { performance in current job. }\end{array}$ & [5] \\
\hline $\begin{array}{l}\text { Self- } \\
\text { regulation } \\
(\mathrm{SR})\end{array}$ & $\begin{array}{l}\text { SR1: I am able to finish my } \\
\text { assignments by deadlines. } \\
\text { SR2: I am able to work even } \\
\text { when there are other interesting } \\
\text { things to do. } \\
\text { SR3: I am able to concentrate on } \\
\text { work subjects. } \\
\text { SR4: I am able to organize my } \\
\text { work. } \\
\text { SR5: I am able to arrange a place } \\
\text { to work at my residence without } \\
\text { distraction. } \\
\text { SR6: I am able to motivate myself } \\
\text { to do work. }\end{array}$ & [43] \\
\hline $\begin{array}{l}\text { Multitasking } \\
\text { Preference } \\
\text { (MP) }\end{array}$ & $\begin{array}{l}\text { MP1: I prefer to work on several } \\
\text { projects in a day, rather than } \\
\text { completing one project and then } \\
\text { switching to another. } \\
\text { MP2: When doing a number of } \\
\text { assignments, I like to switch back } \\
\text { and forth between them rather } \\
\text { than do one at a time. } \\
\text { MP3: I like to finish one task } \\
\text { completely before focusing on } \\
\text { anything else. [R] } \\
\text { MP4: When I have a task to } \\
\text { complete, I like to break it up by } \\
\text { switching to other tasks } \\
\text { intermittently. }\end{array}$ & [29] \\
\hline
\end{tabular}

